\title{
ANMERKUNGEN ZU EINEM ASPEKT BARBARISCHER BILDKUNST IN DER RÖMISCHEN KAISERZEIT UND ZUR ANHALTENDEN VERNICHTUNG EUROPÄISCHEN KULTURERBES
}

\author{
J A N SCH USTER (1)
}

\begin{abstract}
Notes on an Aspect of Barbarian 'Pictorial' Art in the Roman Iron Age and the Ongoing Destruction of European Cultural Heritage. The so-called bulls-head brooches are one of the most remarkable results of Roman Period barbarian art. Until now they were known mostly from the regions of the Western Balts and the neighbouring Wielbark culture in the North-Eastern part of Central Europe. The interesting question where those brooches were created was discussed broadly throughout many years. New finds - unfortunately all gathered by illegal metal detecting raids and offered for sale - shed a new light on the issue. Found at the Ukraine they show that the appearance of bulls-head brooches has to be seen in a broader, supra-cultural context. All specimen can be dated in a relatively short period of 60-70 years in the time before and after $200 \mathrm{AD}$. The same applies to so-called duck brooches that were known from a few sites only. All new-found brooches were offered for sale at East European web sites. In the second part of the paper I discussed the problem, how archaeology should treat such finds.
\end{abstract}

Keywords: Ukraine, Roman Iron Age, bulls-head brooches, duck brooches, illegal detector finds.

Ein bemerkenswertes Ergebnis kunsthandwerklichen Schöpfens während der Römischen Kaiserzeit im „barbarischen“ Teil Europas sind recht selten auftretende Fibeln mit einer plastischen Verzierung am Fußabschluss, die entweder als gehörnter Tierkopf oder nur als Hörner selbst ausgebildet ist. ${ }^{1}$ In der Regel wird davon ausgegangen, dass es sich bei den Darstellungen um Rinder handelt, wobei als Parallelen und Deutungsgrundlagen zumeist Trinkhornendbeschläge in Rinderkopfform sowie kleine Rinderfiguren aus Kupferlegierung (Andrzejowskil Cieśliński 2007, 295 ff; Gandert 1957; Nowakowski 1989; 2016b; Rasmussen 2007; Schoknecht 2006; Schuster 2001, 417 ff.; Schuster/Dulęba 2012; Stenberger 1946; Thrane 1989; Tischler 1950) herangezogen werden. Innerhalb der beiden letztgenannten Fundgruppen gibt es Stücke, die recht realistisch geformt sind und an der Abbildung eines Rindes keinen Zweifel lassen. Für andere, stärker stilisierte, kann nur aufgrund der eindeutigeren Exemplare angenommen werden, dass eine Rinderdarstellung intendiert war. Gleiches gilt auch für die eingangs erwähnter Fibeln. Zwar wurde für diese auch eine alternative
Interpretation mit Blick auf das aus der mittelmeerischen und germanischen Bildkunst bekannte Motiv „gehörntes Pferd" erwogen, ${ }^{2}$ doch werde ich im Folgenden die griffige Bezeichnung „Rinderkopffibeln" verwenden. Hinsichtlich einer eindeutigen Entscheidung für die ausschließliche Interpretation als gehörntes Pferd sehe ich keinen Raum.

Die Trinkhornbeschläge, die Rinderfiguren und die Fibeln mit Rinderkopf- oder Hörnerabschluss gehören zu den frühen, vorvölkerwanderungszeitlichen Zeugnissen einer Bildersprache, die ausweislich der weiträumigen - aber jeweils andere Schwerpunkte aufweisenden - Verbreitung in vielen Regionen von Nord- bis Mitteleuropa verstanden wurde. Diese und auch weitere, mitunter sehr versteckt platzierte figürliche Darstellungen sind aber nicht sehr zahlreich, so dass J. Werner bezogen auf die im Zentrum seiner Studie stehende ethnische Gruppe - die berühmte These des „bilderfeindlichen Germanen“ aufstellen konnte (Werner 1966, 38), die von F. Maier - bezogen auf die ältere Römische Kaiserzeit folgendermaßen auf den Punkt gebracht wurde: „,... im übrigen hält sich

\footnotetext{
1 Unberücksichtigt bleiben zwei völkerwanderungszeitliche Stücke aus Masuren, die vollständig als Tier gestaltet sind und auch keine zeitliche Verbindung zu den mittelkaiserzeitlichen Fibeln haben (vgl. Nowakowski 2016a; 2016b, 134).

2 Schulte 2011, 70 ff. mit Berufung auf Oxenstjerna 1956, 37 ff; 47 und Beilke-Voigt 2006, 96 f.; ähnlich auch Nowakowski 2016b, 135 f. Zum Motiv des gehörnten Pferdes in der germanischen Kunst: Pesch 2011a; 2011b. Vgl. auch Skvorcov/Pesch 2011, 426 ff. Das gleiche Problem betrifft im Übrigen auch kleine hallstattzeitliche Tierplastiken, bei denen oft nur die Anwesenheit von Hörnern über die Zuweisung zur Gruppe der Pferde- oder zur Gruppe der Rinderdarstellungen entscheidend zu sein scheint (siehe Teßmann 2009). Ein Diskussionsbeitrag zum Thema der Erkennbarkeit und Unterscheidbarkeit von gehörnten Pferden gegenüber Rindern: Hegewisch 2018, 152 ff.
} 


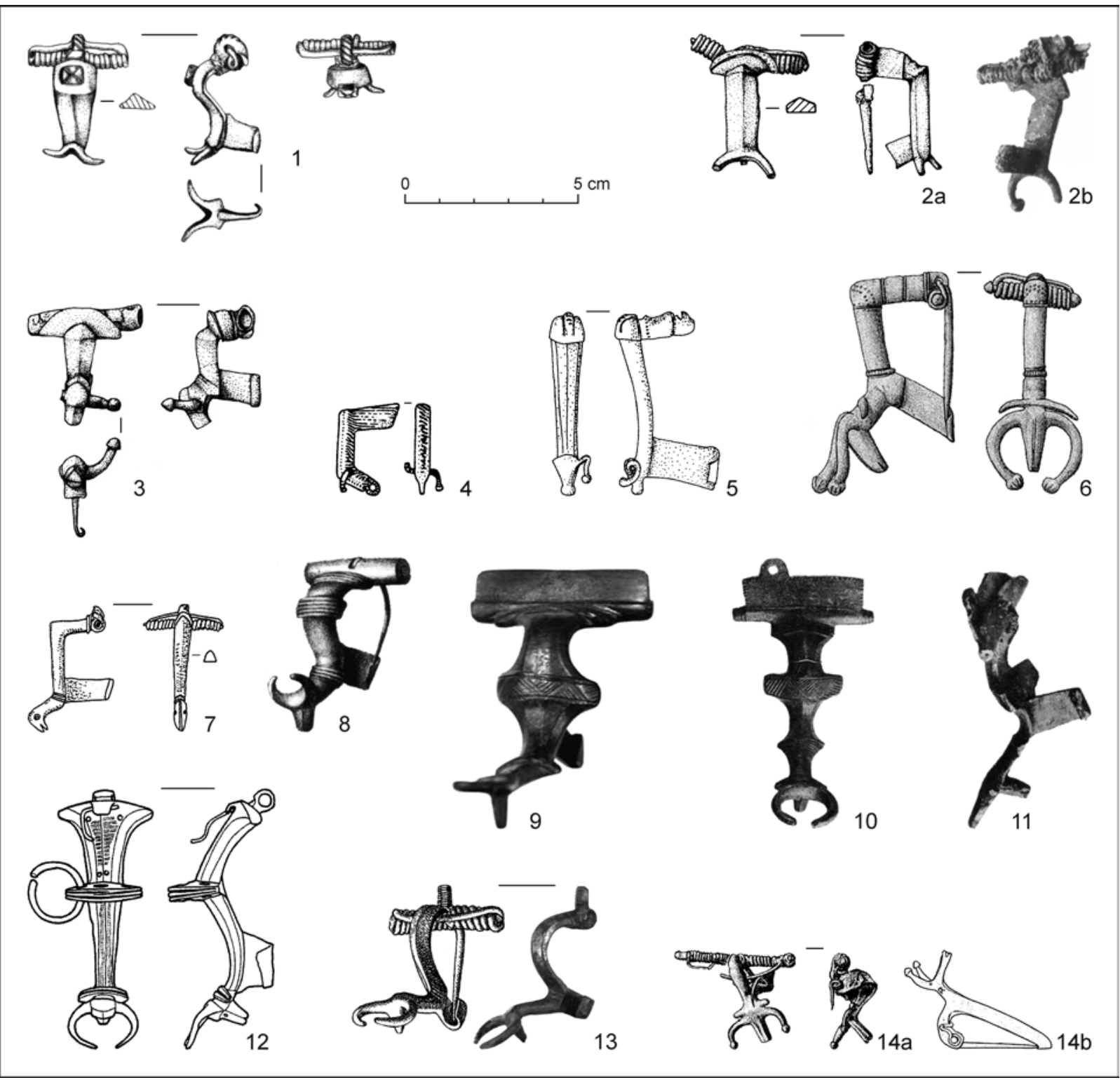

Abb. 1. Bislang bekannte mittelkaiserzeitliche Rinderkopffibeln. 1 - Opalenie (Nr. 8); 2a - Groß-Linichen/Świerczyna (Nr. 9); $2 \mathrm{~b}$ - älteres Foto der Fibel mit anderem Erhaltungszustand; 3 - Kraśnik Piaski (Nr. 2); 4 - Ringelsdorf (Nr. 22); 5 - „Transsilvanien“ (Nr. 24); 6 - Mingfen/Miętktie (Nr. 4); 7 - Łubiana (Nr. 3); 8 - Gruneiken/Grunajki (Nr. 1); 9 - Klein Puppen/Spychówko (Nr. 7); 10, 11 - Moythienen/Mojtyny (Nr. 5); 12 - Červonochyžynci (Nr. 11); 13 - Nikutowen/Nikutowo (Nr. 6); 14a - Zauschwitz (Nr. 23); 14b - Rekonstruktion.

das germanische Handwerk an das Prinzip absoluter Figurenlosigkeit“ (Maier 1981, 350). In der Zwischenzeit ist sie aber ins Wanken geraten, ${ }^{3}$ Inspirationen zum Einsetzen bildlicher Darstellungen im germanischen Kunsthandwerk aus anderen Kulturgebieten sind vielfältig und treten zu verschieden Zeiten auf. Den größten Einfluss hatten unbestritten die keltische und die römische Welt (Blankenfeldt 2007,
105), ${ }^{4}$ wobei im Fall des Themas „Rind/Stier“ besonders auf ostkeltische Statuetten und Anhänger aus Kupferlegierung der Spätlatènezeit hinzuweisen ist (Pieta 2006; 2010, 327 f., bes. Fototaf. 31; 32; 42). ${ }^{5}$

Bislang war eine sehr begrenzte Zahl von mittelkaiserzeitlichen Rinderkopffibeln bekannt, die vor allem im Gebiet der Bogaczewo-Kultur des westbaltischen Kulturkreises sowie der Wielbark-

\footnotetext{
3 Vgl. Blankenfeld 2007; 2015.

4 Vgl. auch Martens 1999.

5 Vgl. auch Maier 1981, 350.
} 
Kultur und mit einigen wenigen Exemplaren in weiter Streuung über Mittel- und Osteuropa gefunden wurden (Andrzejowski/Cieśliński 2007, Abb. 18; Maczyńska 2011, Abb. 21; Nowakowski 1989, Abb. 4; 2016b, Abb. 1; Schuster 2001, Abb. 3.). Zwischenzeitlich kamen aber weitere Funde in Ost- und Südosteuropa zu Tage, die den geographischen Rahmen des Auftretens solcher Spangen stark erweitern, jedoch leider zu einem Großteil bei Raubzügen mit Metalldetektoreinsatz geborgen wurden. ${ }^{6}$ Der Umgang mit diesen Stücken berührt ein wissenschaftsethisches Problem, worauf ich im zweiten Teil des Beitrages zurückkomme.

Die bekannten Rinderkopffibeln repräsentieren sehr verschiedene Formen, wobei sich aber gewisse Wiederholungen zeigen. Völlig richtig haben J. Andrzejowski und A. Cieśliński angemerkt, dass die Zuweisung aller masurischen "Rinderkopffibeln" durch Th. Hauptmann zur Variante 3 seiner Serie 3 „Masurisch-samländische Gruppe der Dreisprossenfibeln" aus formal-typologischen Gründen nicht haltbar ist (Andrzejowski/Cieśliński 2007, 292, Anm. 41). Das Stück von Gruneiken/Grunajki (Abb. 1: 8) entspricht eher den Fibeln Hauptmann Serie 4 „frühe Dreisprossenfibeln im Baltikum", die beiden Fibelpaare von Moythienen/Mojtyny und Klein Puppen/Spychówko (Abb. 1: 9-11) gehören zu den Dreisprossenfibeln masurischer Form. ${ }^{7}$ Manche von diesen verfügen über eine plattenartige Fortsetzung der Scharnierhülse, die durchlocht sein kann und in diesem Fall zur Befestigung einer weiteren Zier, vermutlich einer zwei Fibeln verbindenden Schnur oder eines Kettchens. Letzteres dürfte auch auf die beiden Rinderkopffibeln von Moythienen/Mojtyny zugetroffen haben.

Die Fibel von Mingfen/Miętkie (Abb. 1: 6) hingegen ist eine Kniefibel ähnlich A 137, deren runde Fußplatte jedoch durch den Rinderkopf ersetzt wurde. Die Fibelform A 137 mit der charakteristischen Betonung des Bügelknicks ist für die das Samland einnehmende Dollkeim-Kovrovo-Kultur typisch und aus anderen Gebieten nicht bekannt (Nowakowski 1998b, 199, Abb. 4). Man sollte also meinen, dass auf dieser Form aufbauende Rinderkopffibeln auch nur im westbaltischen Kulturgebiet auftreten können. Tatsächlich war die Fibel von Mingfen/ Miętkie lange Zeit ein Einzelstück, nun aber lassen sich ihm drei in weiter Entfernung geborgene Funde zur Seite stellen. Eine Rinderkopffibel aus „Transsilvanien“ (Siebenbürgen) verfügt über einen knieförmigen Bügel mit starker Betonung des Knicks, der "Rinderkopf" ist in diesem Fall klein und wirkt fast wie ein umgearbeiteter Fußknopf (Abb. 1: 5). Leider ist unbekannt, ob die Fibel aus dem barbarischen oder aus dem provinzialrömischen Teil Siebenbürgens stammt. Es wäre denkbar, dass es sich um die Umsetzung einer provinzialrömischen Kniefibelform handelt. ${ }^{8}$ Anzumerken ist allerdings, dass es auch eine Reihe barbarischer Kniefibeln mit der Bügelknickbetonung gibt, deren Fuß glatt endet, also ohne Fußscheibe. ${ }^{9}$ Es ist somit durchaus möglich, dass die Form mit Fußscheibe A 137 und die Form mit Rinderkopf gleichermaßen Derivate derartiger "einfacher" Fibeln darstellen. ${ }^{10}$ Eine weitere Rinderfibel mit Bügel der Form A 137 wurde in der Umgebung von Odessa gefunden (Abb. 2: 2), hinzu tritt noch ein zweites Stück aus der Ukraine, dessen Fundregion leider unbekannt ist (Abb. 3: 2). Sein Bügel ist allerdings nicht recht-, sondern stumpfwinklig geknickt. Will man nicht annehmen, dass es sich bei den drei Neufunden um „Importe“ aus dem westbaltischen Kulturgebiet handelt, muss man eine - bislang noch nicht gut belegte - weiträumige Verbreitung der Grundform annehmen. ${ }^{11}$

Eine Fibel mit knieförmigem Bügel ist ebenfalls die Ausgangsform einer Gewandschließe von Ringelsdorf (Abb. 1: 4), die allerdings schwerlich „Rinderkopffibel“" genannt werden kann. Aufgrund der hornförmigen Fortsätze (Einsätze?) am Bügelknick ergibt sich die Frage, ob auch dieses Stück der Gruppe der hier besprochen Fibeln anzuschließen ist. Es steht den elbgermanischen Kniefibeln wie A 141 oder A 143 nahe, könnte aber aufgrund des hohen und schräg gestellten Nadelhalters (der eine Anhebung des Fußabschnittes des Bügels zur Folge

\footnotetext{
6 Sie wurden auf den Internetportalen www.violety.com und www.domongol.org angeboten [Zugriffe 2018-2020].

7 Zu dieser Fibelform zuletzt umfassend: Szter 2010, 214 ff., Abb. 10-14.

8 Vgl. Funde aus Porolissum (Cociş 2004, Taf. LXXX: 1219-1221). Hier werden sie explizit als Form A 137 angesprochen (ebd. 102 f.). Hinsichtlich der Kniefibeln ähnlich A 137 äußerte M. Mączyńska $(2011,50)$ die interessante Vermutung, dass es sich bei diesen um Umsetzungen provinzialrömischer Formen, etwa Kovrig 104/104a, handeln könnte.

9 Z. B. Weklice, woj. warmińsko-mazurskie, Grab 83 (Natuniewicz-Sekuła/Okulicz-Kozaryn 2011, Taf. XXX: 83: 1); Łubiana, pow. Kościerzyna, woj. pomorskie (Mączyńska 2011, 349, Taf. 8: FB 115). Die typologische Ansprache nach Almgren gestaltet sich entsprechend schwierig und es wird sowohl auf die Form A 132 als auch auf die Form A 137 verwiesen (Maczyńska 2011, 42; vgl. auch Szter 2010, 211).

${ }^{10}$ Die Frage wurde schon von E. Droberjar (2012) angesprochen, bedarf aber noch einer eingehenderen Analyse.

${ }^{11}$ Belege gibt es bislang aus den Gebieten des westbaltischen Kulturkreises, der Wielbark - sowie der Przeworsk-Kultur, aus dem nördlichen Vorland der mittleren Donau sowie aus der Ungarischen Tiefebene (Mączyńska 2011, 342).
} 

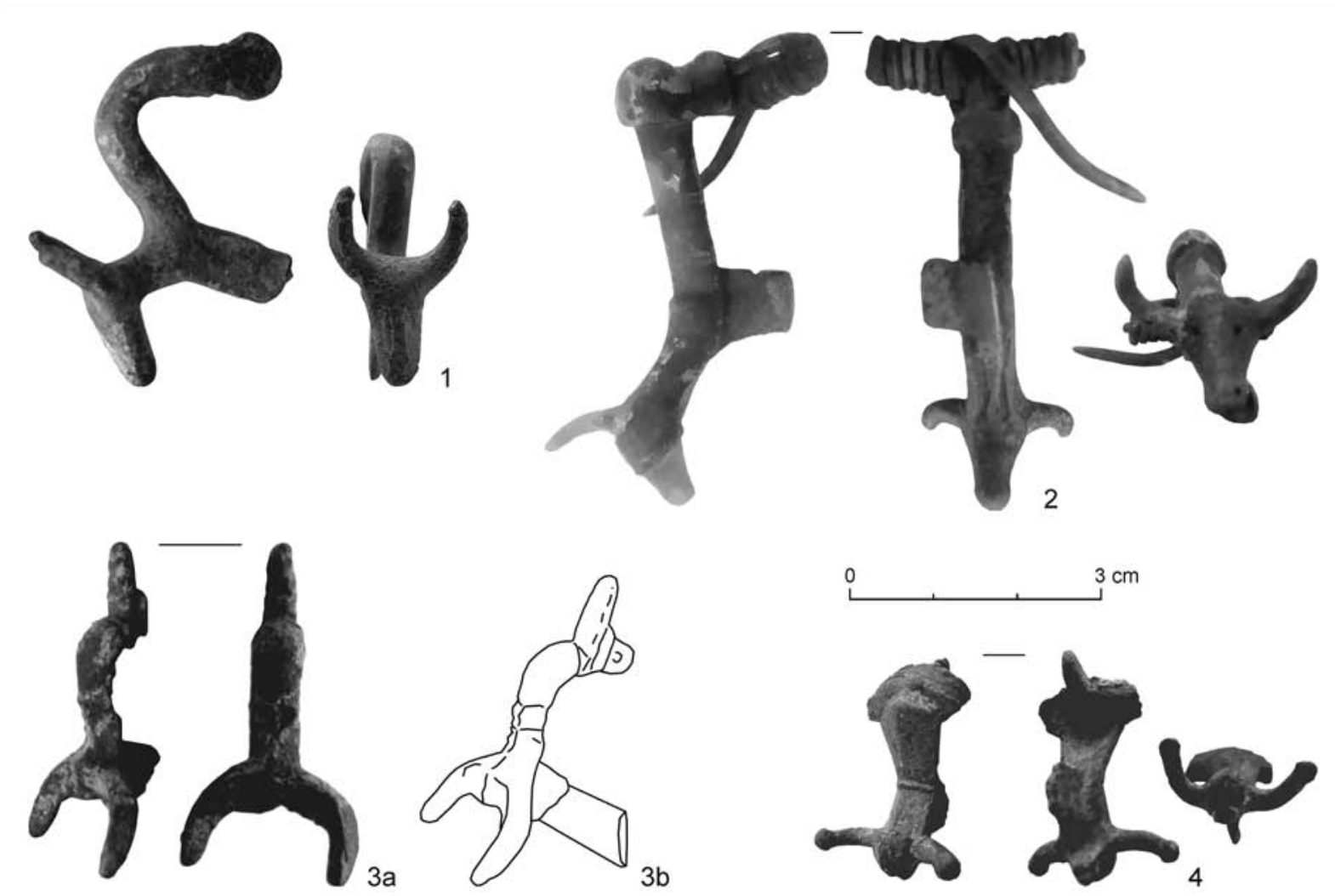

Abb. 2. Rinderkopffibeln aus der Ukraine mit bekannter Fundregion. 1 - Medžybiž (Nr. 13); 2 - Odes'ka oblast' (Nr. 14); $3 a$ - Dnipropetrovs'ka oblast' (Nr. 12); 3b - Rekonstruktion; 4 - Chmel'nyc'ka oblast' (Nr. 10).

hatte) schon der jüngerkaiserzeitlichen Gruppe A VII (hier der Form A VII 1,1 = sog. Kniefibelderivate: Schulte 2011, 56 ff., Abb. 29) zugewiesen werden. Offen bleibt, ob es sich bei den Fortsätzen mit kugelförmiger Verdickung des Abschlusses tatsächlich um Hörnerdarstellungen handelt oder nicht schlicht um eine nun die ehemals vorhandenen Zieraufsätze aus Perldraht entbehrende, verbogene Bügelsprosse wie bei Fibeln A 144, die bei derartigen Fibeln auch genau an der gleichen Stelle des Bügels sitzt wie die Fortsätze des Ringelsdorfer Exemplars.

Als Kniefibelderivat kann die Rinderkopffibel von Łubiana in Pommern gelten (Abb. 1: 7). Der Bügel ist exakt rechtwinklig geknickt und seine Teilabschnitte verlaufen geradlinig. Im Hort selbst gibt es einige Parallelstücke, allerdings mit Kopfund Fußknopf (Mączyńska 2011, 349, Taf. 8: F8, F73, F 76, F89, FB 91, 106, FB 89, FB 91)..$^{12}$ Diese wurden als „Kniefibeln der Form Łubiana“ bzw. als „,Kniefibeln sarmatischen Typs" bezeichnet, die Entsprechungen in der Provinz Dacia haben (Maczyńska 2011, 45 f., Abb. 18). ${ }^{13}$ Derartigen Stücken kann auch eine Rinderkopffibel unbekannter Lokalisierung aus der Ukraine (Abb. 3: 1) zugewiesen werden, deren Kopf wie bei manchen Stücken aus der Dacia leicht verdickt ist.

Bei dem Exemplar von Červonohižinci ist die typologische Herleitung nicht so einfach (Abb. 1: 12), in der Publikation wird eine Verbindung zu den Dreisprossenfibeln vermutet. ${ }^{14}$ Aus meiner Sicht handelt es sich wohl eher um eine osteuropäische Spangenform aus dem Umfeld später kräftig profilierter Fibeln, deren Entwicklungslinie von Fibeln der masowischen Variante, möglicherweise auch von Fibeln A 84 (Dabrowska 1993-1994, 5 ff., $10 \mathrm{ff}$.) ausging. Fibeln der masowischen Variante sind vor allem aus dem östlichen Teilgebiet der Przeworsk-Kultur bekannt (Andrzejowski/Cieśliński

\footnotetext{
${ }^{12}$ Vgl. auch ein silbernes Exemplar aus Grab 605 von Weklice, woj. warmińsko-mazurskie (Natuniewicz-Sekuła 2015-2016, 236, Abb. 2: 2).

${ }^{13}$ Allerdings gibt es aus der Dacia nicht viele Belege, die auch andere Bügelausformungen haben (vgl. Cociş 2004, Taf. CXIV: 1618-1625)

14 Ähnlich auch Nowakowski 2016b, 132 f.
} 


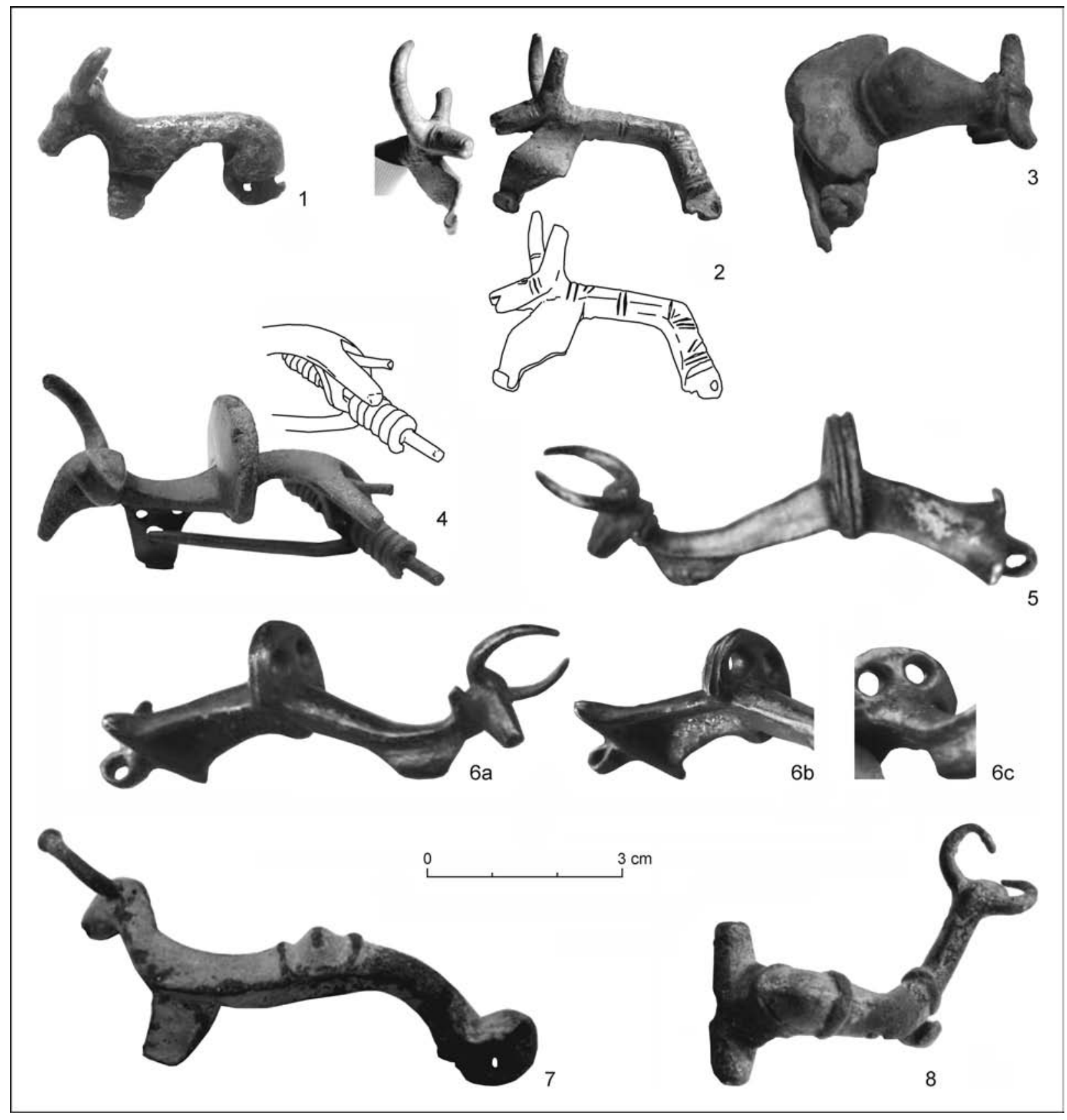

Abb. 3. Rinderkopffibeln aus der Ukraine bzw. Osteuropa, deren Fundregionen unbekannt sind. 1 - Nr. 15; 2 - Nr. 16; 3 - Nr. 17; 4 - Nr. 18; 5 - Nr. 19; 6 - Nr. 25, mit Details; 7 - Nr. 20; 8 - Nr. 21.

2007, 289, Abb. 12), streuen aber auch weit in die Ukraine und wurden hier offenbar zu anderen Formen weiterentwickelt (Andrzejowski, im Druck). Sie zeichnet ein flacher, aber seitlich verbreiterter Kopf aus, der Bügel ist oft breit und flach. Zwei weitere Rinderkopffibeln aus der Ukraine, deren Fundregion nicht bekannt ist (Abb. 3: 4, 5, 7), sowie ein Stück, das mutmaßlich auch aus der Ukraine stammt (Abb. 3: 6), scheinen ebenfalls osteuropäische Derivate später kräftig profilierter Fibeln zu repräsentieren. Die Wiederholung mehrerer Merkmale bei drei dieser Spangen spricht für einen regionalen Typ mit Bezug zu einem Gebiet irgendwo in Osteuropa, mutmaßlich in der Südwestukraine.

Eine weitere Gruppe von Rinderkopffibeln zeichnet ein breiter Bügel mit Mittelgrat aus, der entweder parallele Seitenkanten aufweist oder V-förmig gestaltet ist. Er hat ferner einen betonten Knick, womit solche Stücke an Kniefibeln erinnern. Oberhalb dieses Knicks befindet sich ein breiter, massiver Kamm, was die Spangen in die Nähe der Kopfkammfibeln stellt. In der Tat steht ein 


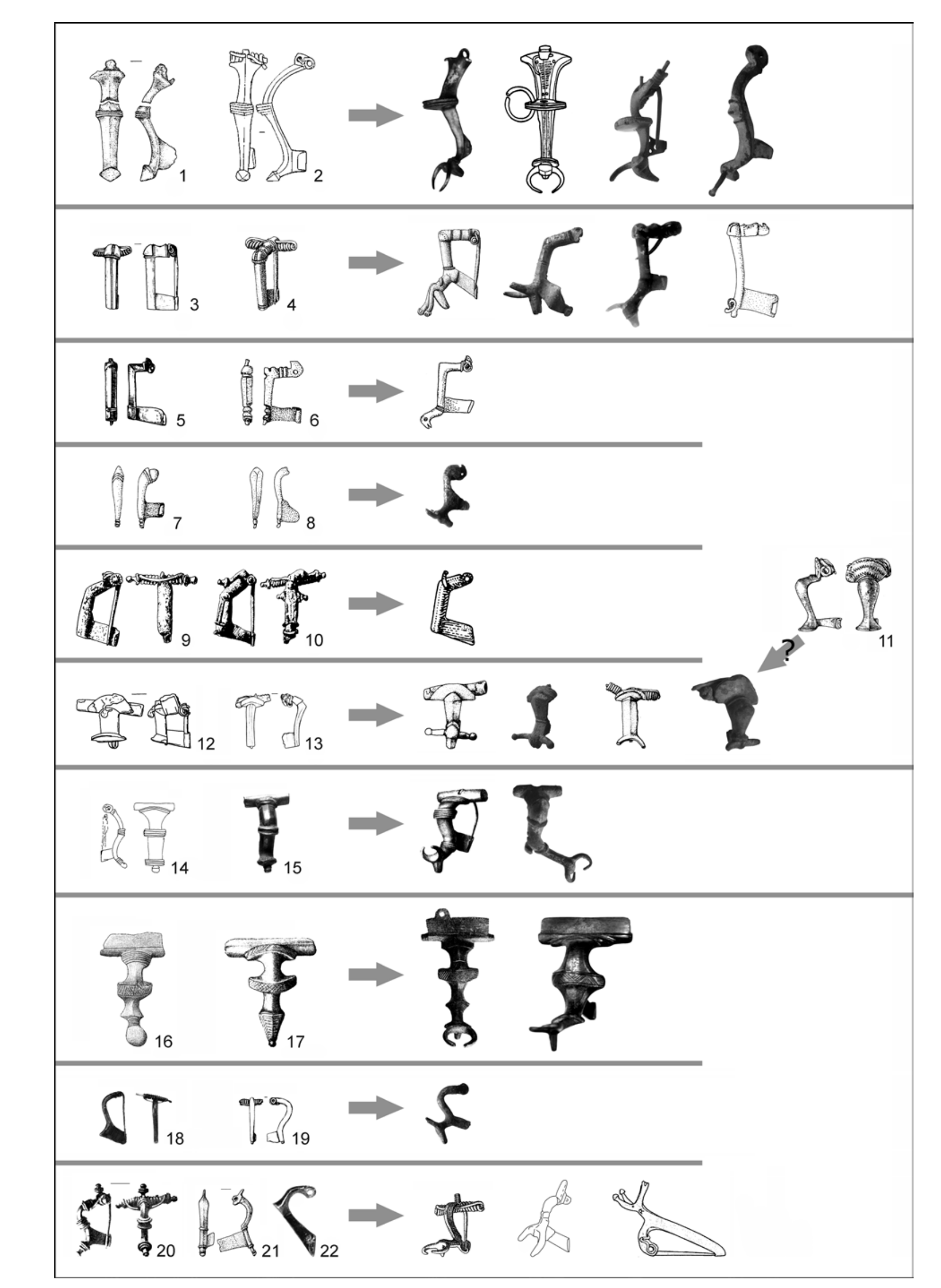


Stück wie jenes von Kraśnik Piaski (Abb. 1: 3) den Fibeln A 125 näher als den Kniefibeln, das ihm durchaus ähnliche Exemplar von Groß-Linichen/ Świrczyna hingegen (Abb. 1: 2) hat eher Merkmale ostmitteleuropäischer Kniefibeln A 132. Die schwer einzuordnende Spange von Opalenie (Abb. 1: 1) gehört wohl auch zu den Kopfkammfibeln und hat Entsprechungen in Fibeln der Formen $3 b, 5 b$ und $7 b$ nach Machajewski. ${ }^{15}$ Ein drittes Stück dieser Gruppe, dessen Fundregion innerhalb der Ukraine nicht mehr ermittelt werden kann, ist gedrungen und verfügt über eine großformatige halbkreisförmige Kopfplatte (Abb. 3: 3). Es wäre denkbar, dass es sich um eine Weiterentwicklung von Fibeln A V, Ser. 8 oder der östlichen Kniefibeln handelt. Allerdings ist es auch nicht unwahrscheinlich, dass eine provinzialrömische Kniefibel mit halbrunder Kopfplatte wie Jobst 13C-D (Jobst 1975, 63 ff.) bzw. A 247 bzw. Merczi Var. B/1-4 (Merczi 2011, 29 ff.) als Vorlage diente. Solche Stücke sind auch aus dem nördlichen Schwarzmeerküstengebiet bekannt (Ambroz 1966, 28). Die typologischen Ausgangsformen sind folglich recht vielfältig und verraten kein einheitliches Muster, wie der Vergleich zeigt (Abb. 4).

Seit langem beschäftigt die Forschung die Frage nach der Herkunft der Rinderkopffibeln. W. Gaerte $(1929,220)$ sprach sich für eine Herleitung der Fibeln mit Rinderkopf bzw. Rinderhörnern aus dem „südrussischen“ Raum aus, wogegen O. F. Gandert $(1957,137)$ mit dem Fehlen von dortigen Belegen argumentierte. M. Mączyńska sah aufgrund der Konzentration von Funden im Gebiet der westbaltischen Bogaczewo-Kultur den Ursprung dieser seltenen Trachtbestandteile in Masuren und sprach die Stücke von Zauschwitz und Červonohižinci als „westbaltische Exporte“ an (Maczyńska 2011, 50), das Exemplar von Groß-Linichen/Świerczyna als einheimische Nachahmung einer westbaltischen Vorlage. Alle sieben Fibeln aus dem Gebiet der Bogaczewo-Kultur interpretiert W. Nowakowski als Produkte eines einzigen Handwerkers, der Inspirationen aus dem Gebiet der Przeworsk-Kultur verarbeitete (Nowakowski 2016b, 136). Allerdings scheinen mir die angeführten Trinkhornendbeschläge in Rinderkopfform aus deren Gebiet als zu schwache Basis für eine solche Annahme, denn ihre Zahl ist nicht gerade überwältigend.

In der auch aus typologischen Gründen als Einzelstück anzusprechenden Fibel von Opalenie an der unteren Weichsel wollten J. Andrzejowski und A. Cieśliński den Prototyp der "gehörnten" Fibeln und das Ergebnis eines formalen Experiments erkennen (Andrzejowski/Cieśliński 2007, 294). Letzteres scheint mir zu "technisch“ gedacht und darf wohl ausgeschlossen werden, wenn man den - freilich nicht erschließbaren, aber wohl vorauszusetzenden - kultischen oder apotropäischen Aspekt berücksichtigt, der zu Fertigung einer Fibel mit Rinderhörnern veranlasste. Das Exemplar von Opalenie gilt als ältestes Stück (der zeitlich bestimmbaren Fibeln) und soll aufgrund der begleitenden Fibeln A 42 (Tuszyńska 2005, 435, Taf. I: 1, 2) in B2a datieren (Nowakowski 2016b, 131). Allerdings ist eine derart frühe Einordnung keineswegs gesichert, da Spangen A 42 auch noch im jüngeren Abschnitt der Phase B2 auftreten können (Chilińska-Früboes 2020, 170 f.). Die Rollenkappenfibel (Eggers/Stary 2001, Taf. 317: 7) aus dem Grabinventar mit gleichfalls nur "gehörnter" Fibel von Groß-Linichen/Świerczyna ist aufgrund des Grades ihrer Beschädigung typologisch nicht genau anzusprechen, eine Bestimmung als frühe Rollenkappenfibel der östlichen Serie (Andrzejowski/Cieśliński 2007, 296; Nowakowski 2016b, 132) ist nicht über jeden Zweifel erhaben. Die Rinderkopffibel selbst gehört in das Umfeld später Fibeln mit Kopfkamm, genauso wie auch die Spange von Kraśnik Piaski, die mit zwei Fibeln A 43 kombiniert ist. Letztere datieren gelegentlich schon in spätes B2, gelten jedoch als Leitform der Subphase B2/ C1a (Mączyńska 2011, 41; Rajtár 2018, 57 ff.). Zum Inventar mit der Kniefibel von Mingfen/Miętkie gehört eine Dreisprossenfibel A 96, womit eine Datierung ebenfalls in die beginnende jüngere

\footnotetext{
${ }^{15}$ Vgl. Machajewski 1998.
}

Abb. 4. Herleitungsschema der verschiedenen Formen der Rinderkopffibeln. 1- Ciebłowice Duże, Grab 108 (PL; Dzięgielewska/Kulczyńska 2008, 34, Taf. LXIX: 108: 1); 2 - Olbia/Parutyne (UA; Ambroz 1966, Taf. 7: 14); 3 - Weklice, Grab 83, (PL; Natuniewicz-Sekuła/Okulicz-Kozaryn 2011, 42, Taf. XXX); 4 - Macharren/Machary (PL; Gaerte 1929, Abb. 168: e); 5 - Museum Brno (CZ; Peškař 1972, Taf. 15: 2); 6 -Porolissum (RO; Cociş 2004, 199, Taf. LXXX: 1221); 7 - Porolissum (RO; Cociş 2004, 199, Taf. CXIV: 1624); 8 - Ilişua (RO; Cociş 2004, 199, Taf. CXIV: 1625); 9 - Zethlingen, Grab 454 (D; Worbs 1979, Taf. 8: 454); 10 - Zethlingen, Grab 17 (D; Worbs 1979, Taf. 10: 17: a); 11 - Museum Olomouc (CZ; Peškař 1972, Taf. 17: 7); 12 Chmielów Piaskowy, Grab 39 (PL; Godłowski/Wichman 1998, 36, Taf. LIX: 7); 13 - Drozdowo (PL; Andrzejowski/Maciałowicz 2017, 217, Abb. 23: 3); 14 - Fürstenau/Leśniewo (PL; Wiśniewska 2011, 125, Taf. V); 15 - Althof-Insterburg, Grab I (RU; Chilińska-Früboes 2020, 37, Taf. 1); 16 - „Ostpreußen” (Nowakowski 1998, 125, Taf. 31: 625); 17 - Fürstenwalde/Poddubnoe (RU; Tischler/Kemke 1902, Taf. II: 14); 18 - Thorsberger Moor, PA 36 (D; Blankenfeldt 2015, 356, Taf. 6); 19 -Malbork-Wielbark (PL; Sekuła 2006, 192, Abb. 1: 13); 20 - Moythienen/Mojtyny, Grab 41 (PL; Hollack/Peiser 1904, 25, Taf. 6); 21 - Sieluń (PL; Prochowicz/Rakowski 2013, 200, Abb. 2: 3); 22 - Thorsberger Moor, PA 38 (PL; Blankenfeldt 2015, 356, Taf. 6). 


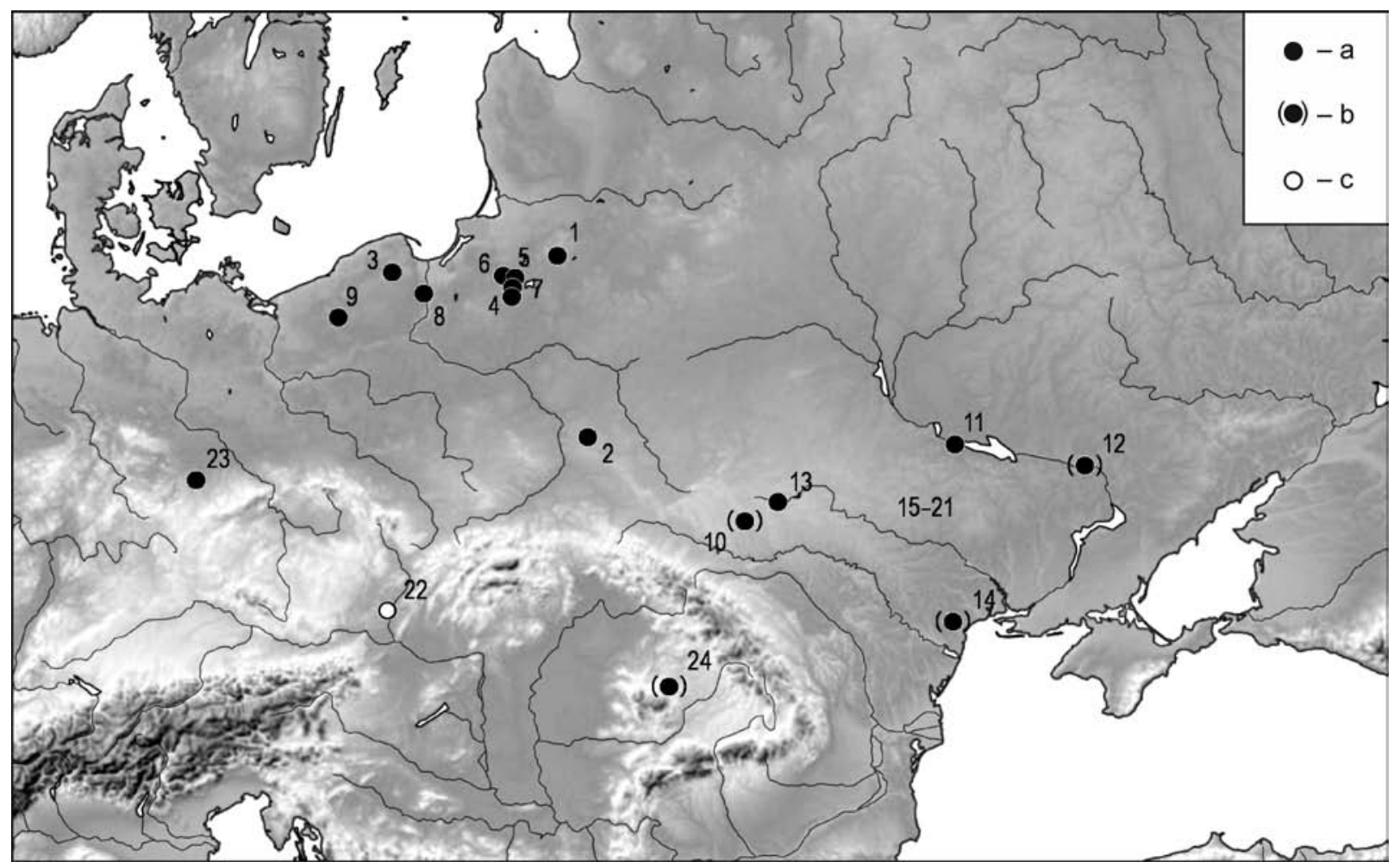

Abb. 5. Verbreitung aller bekannten Rinderkopffibeln. Die Nummern entsprechen der Nummerierung in der Fundliste. Legende: a - sicherer Fund; b - Fundort nur annähernd bekannt; c - unsicherer Fund.

Kaiserzeit (Subphase B2/Cla) abgesichert ist (Nowakowski 2016b, 131). Die Dreisprossenfibeln der masurischen Form von Klein Puppen/Spychówko und Moythienen/Mojtyny können in Cla datiert werden (Nowakowski 2016b, 132), die typologisch jüngeren Fibeln mit hohem Nadelhalter von Nikutowen/Nikutowo und Zauschwitz in die Phase C1 (vermutlich in deren älteren Abschnitt).

In den sich recht klar abzeichnenden Horizont der Verwendung von "gehörnten" und von Rinderkopffibeln, der in die (wohl fortgeschrittene) zweite Hälfte des 2. Jahrhunderts und in die ersten Jahrzehnte des 3. Jahrhunderts fällt und somit etwa ca. 60-70 Jahre markiert, passen sich auch die Neufunde trotz ihrer unbekannten Zusammenhänge und Fundvergesellschaftungen ein. Die Spange ohne bekannte Fundregion mit halbkreisförmiger Kopfplatte zeigt - wie dargelegt - Anklänge an provinzialrömische Kniefibeln Jobst 13C-D. Solche Stücke datieren nach I. Kovrig ab der zweiten Hälfte des 1. Jahrhunderts (Kovrig 1941, 120), in jüngeren Arbeiten werden sie allerdings in das fortgeschrittene 2. und in die erste Hälfte des 3. Jahrhunderts datiert (Böhme 1972, 18 f.; Merczi 2012, 494; Petković 2010, 363; Redžić 2007, 33). Die übrigen Funde lassen sich typologisch schon bekannten Rinderkopffibeln anschließen und sprengen den genannten Zeitrahmen nicht.

Das Auftreten dieser Funde in der heutigen Ukraine dürfte noch Anlass für weitere Diskussionen sein, wird doch der Verbreitungsschwerpunkt der mittelkaiserzeitlichen Rinderkopffibeln deutlich nach Südosten erweitert (Abb. 5); ihr Erscheinen dort kann aus chronologischen Gründen keineswegs mit der Černjachov-Kultur verknüpft werden. Somit handelt es sich bei den Rinderkopffibeln offenbar um mindestens drei Kulturräume übergreifende Funde (germanischer Kulturraum, westbaltischer Kulturraum und?). Dieser Umstand verdient Beachtung, denn Arbeiten zur figürlichen Darstellung und zur germanischen Religion fokussieren allgemein zu stark auf Mittel- und Nordeuropa, es fehlen darin zumeist Verweise auf das ostmittelund osteuropäische Fundgut. ${ }^{16}$ Das führt zu einem verzerrten Abbild der Entwicklungsgeschichte germanischer Bildkunst und zur Ausblendung von entscheidenden Impulsen aus nord- und südöstlich an den germanischen Raum angrenzenden Gebieten. So zeichnet sich zum Beispiel immer deutlicher $a b$, dass die ältesten Vertreter der rinderkopfförmigen, zumeist mit Skandinavien assoziierten Trinkhornendbeschläge mit Rinderkopf aus dem heute

\footnotetext{
${ }^{16}$ Vgl. Blankenfeldt 2007; 2015; Rasmussen 2007.
} 
polnischen Raum Mitteleuropas vorliegen (Dulębal Schuster 2012, 393 $)^{17}$ und das Eindringen von Inspirationen unmittelbar aus den spätkeltischen Siedlungsgebieten zwischen Alpenraum und mittlerer Donau widerspiegeln könnten. Auch die Thematik der Rinderkopffibeln muss vor diesem Hintergrund noch einmal neu betrachtet werden, was aber den Rahmen des Beitrages sprengen würde.

Ein Kommentar ist noch hinsichtlich der aus der Ukraine vorliegenden Rinderkopffibeln nötig. Sie wurden sämtlich durch Sondengänger entdeckt und standen zum Verkauf. Das Problem der illegalen Sondengängerei ist hinlänglich bekannt und vielfach diskutiert, daher ist es an dieser Stelle auch entbehrlich, die Schädlichkeit derartigen Tuns für Wissenschaft und Gesellschaft erneut zu betonen. Die Zahl der zu diesem Thema erschienenen Literatur ist äußerst umfangreich und auf die Anführung entsprechender Sammelbände, Monographien und Aufsätze wird an dieser Stelle verzichtet. Ich möchte hier nur auf einen Aspekt des Phänomens illegaler, zumeist kommerzieller Artefaktsuche mithilfe des Metalldetektors eingehen: die Reaktion der Fachwelt auf in Bild bekannt gewordene Funde, also auf die auf entsprechenden Internetseiten präsentierten und zum Verkauf angebotenen Artefakte. Es wäre natürlich aus rein wissenschaftsethischen Gründen vertretbar, diese Stücke zu ignorieren, um den Akteuren, die den Rahmen der Legalität verlassen haben, nicht noch ein ihre Tätigkeit gewissermaßen rückwirkend legitimierendes Podium zu bieten. Ein solches Vorgehen würde aber nichts an der Tatsache ändern, dass diese Artefakte nun einmal „da sind“ (und es im Übrigen vor der Auffindung auch schon waren), sie haben allein schon durch ihre Existenz einen wissenschaftlichen Wert. Die sich aus diesem Konflikt ergebene Frage lautet auf den Punkt gebracht: Kann ich wissenschaftliche Arbeiten $\mathrm{zu}$ entsprechenden Artefaktgruppen und zu auf ihrer Analyse basierenden, verallgemeinernden Untersuchungen verfassen, wissend, dass es weitere Funde gibt, die ich aufgrund ihrer "Herkunft" unberücksichtigt lasse, die aber auf meine Untersuchungen, Argumentationen und Schlussfolge- rungen Einfluss haben können? Noch zugespitzter kann man es folgendermaßen formulieren: Arbeite ich unter bewusster Weglassung solcher Funde wissenschaftlich korrekt? Um es an dieser Stelle noch einmal ganz deutlich zu sagen: Ich verurteile jegliche illegale, metalldetektorgestützte Sammlertätigkeit und auch den Handel mit archäologischen Artefakten. Leider werden wir dieser Plage nicht Herr und müssen uns daher Strategien überlegen, wie wir mit den Unmengen von vorhandenen, leider nur rumpfartigen Informationen umgehen. Nicht nur in der Ukraine werden archäologische Fundplätze geplündert, aber hier in extrem zu nennender Intensität. Ganze Gräberfelder werden durchkämmt und kommerziell ausgebeutet, wie unter anderem Fotos von angehäuften Fibeln, Schnallen, Riemenzungen und dergleichen belegen. Es wird Kulturgut in einem Maße zerstört und unterschlagen, dass viele Fragen, Aspekte und Zusammenhänge der Frühgeschichte in Ost-, Mittel- und Nordeuropa nur noch schwer oder unter Umständen gar nicht mehr zu klären sein werden. Dabei zeigen die Detektorfunde eindeutig, dass die Landschaften zwischen (Westlichem) Bug, Karpatenbogen, Dnepr und Schwarzem Meer einen Schlüsselraum für das Verständnis vieler frühgeschichtlicher Entwicklungsprozesse im Spannungsfeld zwischen barbarischer Welt (einschließlich Skandinavien) und Rom/Ostrom ${ }^{18}$ sowie zwischen Mittel- und Osteuropa bilden. Mittlerweile zeichnen sich völlig neue - aufgrund der illegalen Sammlertätigkeit leider oftmals nur unscharf erkennbare - Fundlandschaften ab, ja Verbreitungsschwerpunkte ganzer Objekttypen verschieben sich nach Osten und das in einem Umfang, den man sich noch vor wenigen Jahren nicht hätte vorstellen können. ${ }^{19}$ Die gesamteuropäische Dimension dieser Vorgänge und Veränderungen ist noch gar nicht richtig abzuschätzen. Daher kommt man aus meiner Sicht nicht umhin, ja ist es nachgerade unsere Pflicht, so viele Daten wie nur irgend möglich zusammenzutragen und zu publizieren. ${ }^{20}$ Das Risiko des Verlustes der - ohnehin schon begrenzten - Informationen ist extrem groß. Die hier diskutierten Rinderkopffibeln sind ein gutes Bei-

\footnotetext{
${ }^{17}$ Funde: Legionowo, pow. Legionowo, woj. mazowieckie (Nowakowski 2017; Orliński 2011); Klein Moitzow, Kr. Greifenberg/ Mojszewko, pow. Gryfice, woj. zachodniopomorskie (Eggers/Stary 2001, 99, Taf. 280: 7); Osiek, pow. Jarocin, woj. wielkopolskie (Pawlak 2008, 212, Abb. 4) - zusammenfassend zur Datierung: Nowakowski 2017, bes. $124 \mathrm{f}$.

18 Siehe beispielsweise die Arbeiten zu römischen Goldmünzen und barbarischen Imitationen und deren Einfluss auf den Beginn einer germanischen Münzprägung - z. B. Bursche 2013; zuletzt: Bursche/Myzgin 2020, bes. Kt. 6.

${ }^{19} \mathrm{Zu}$ entsprechenden, eigentlich für die Przeworsk-Kultur typischen Funden jetzt eindrucksvoll: Andrzejowski, im Druck. Zu goldenen Lunula-Anhängern siehe Skvorcov 2014, Abb. 4. Siehe auch Funde von Hemmoorer Eimern aus der Ukraine: Levadal Potupčik 2017; Nadvirniak/Pohorilec' 2014; Petrauskas/Didenko 2019.

${ }^{20}$ H. J. Eggers $(1951,12)$ formulierte dies - zwar bezogen auf andere Zeiten und Umstände, aber dennoch immer noch gültig folgendermaßen: „... scheint der Druck und die dadurch bedingte rasche Dezentralisierung das einzig wirksame Mittel zu sein, ein
} wissenschaftliches Material zu retten." 


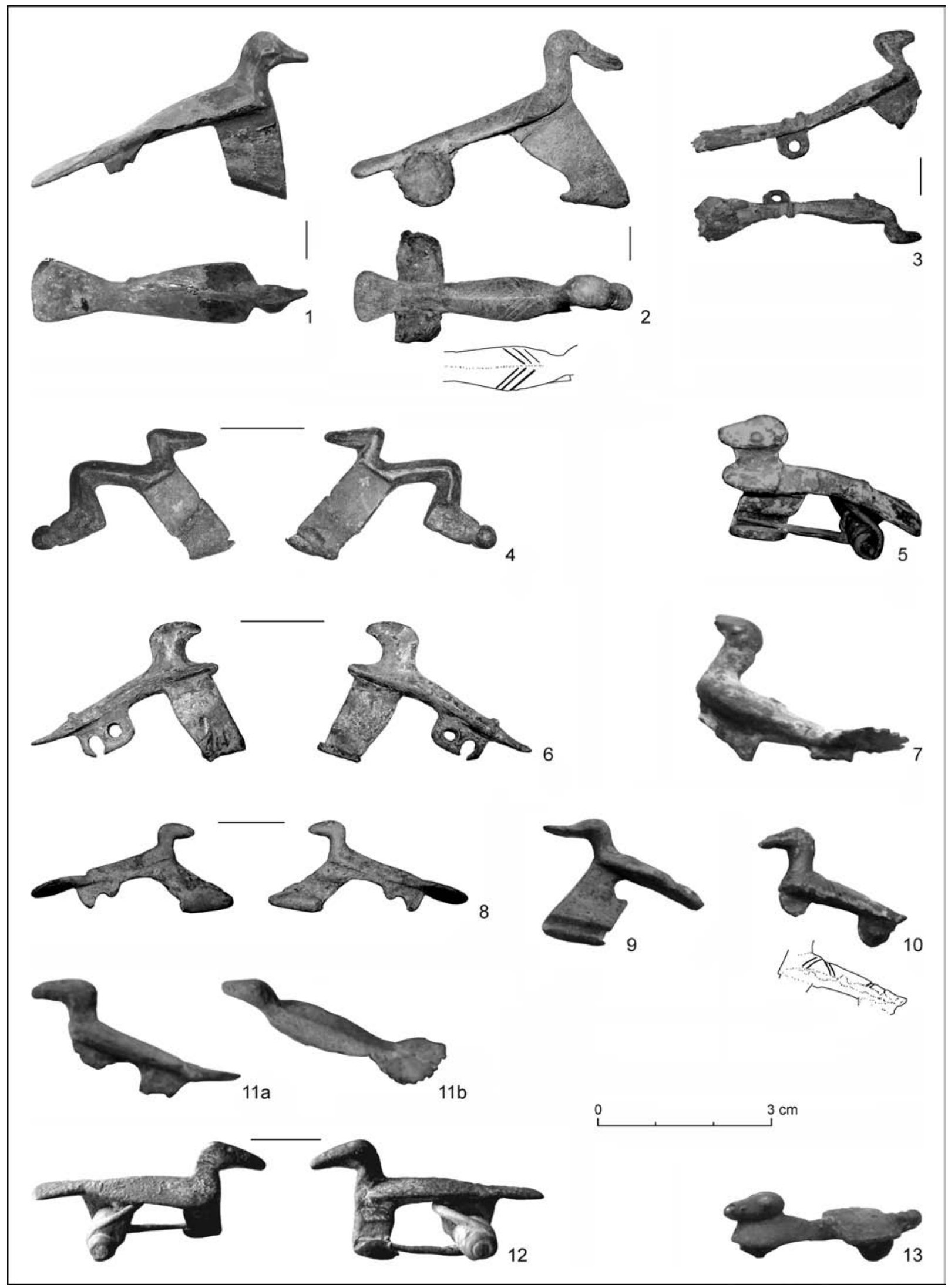

Abb. 6. Neufunde von Fibeln vom Typ Masłomęcz und verwandter Fibeln (11 [?] und 12) aus der Ukraine. 1 - L'vivs'ka oblast'; 2-6, 8-Rivnens'ka oblast'; 7, 9, 10, 13 - Dnipropetrovs'ka oblast'; 11 - Chmel'nic'ka oblast', Deražnians'kiy rajon; 12 - Osteuropa. Nr. 13 wohl nicht vom Typ Masłomęcz, eher spätkaiserzeitlich. 


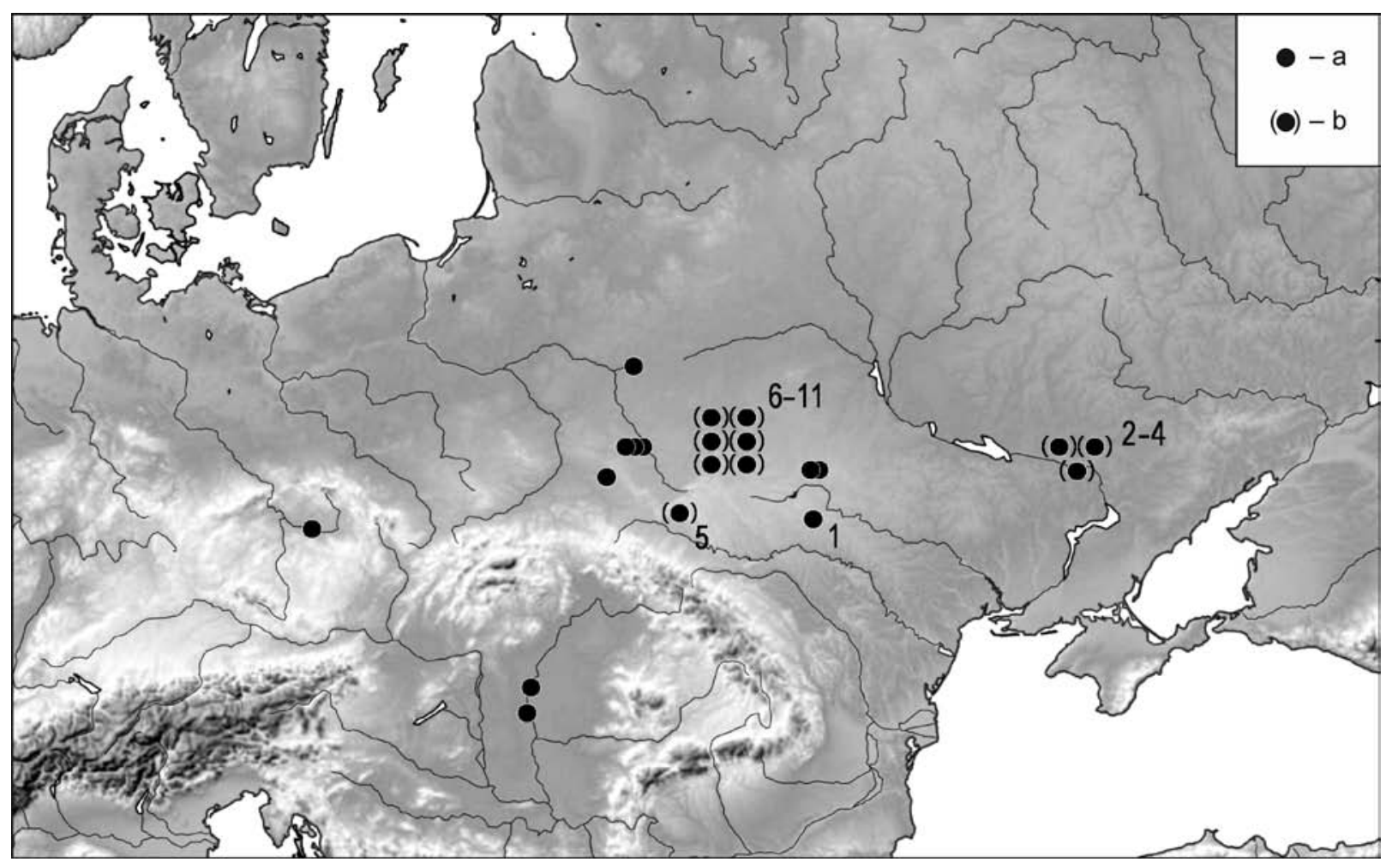

Abb. 7. Verbreitung aller bekannten Fibeln vom Typ Masłomęcz (nicht nummerierte Fundplätze siehe Droberjar 2018). 1 - Chmel'nic'ka oblast', Deražnians'kiy rajon; 2-4 - Dnipropetrovs'ka oblast'; 5 - L'vivs'ka oblast'; 6-11 Rivnens'ka oblast'. Legende: a - sicherer Fund; b - Fundort nur annähernd bekannt.

spiel: Alle auf Abb. 3 präsentierten Stücke stammen sämtlich aus der Ukraine, aber leider kennen wir die Fundregionen nicht mehr. ${ }^{21}$ Sie waren bekannt, die Angaben sind aber aufgrund des Versagens von Datenträgern verloren gegangen. ${ }^{22}$

Aus dem oben angeführten Grund lege ich hier ebenfalls mit dem Metalldetektor entdeckte Funde von den mit den Rinderkopffibeln thematisch verwandten, barbarischen Vogelfibeln mit hohem Nadelhalter vor (Abb. 6), ohne sie hier genauer zu diskutieren. Es kann auf die entsprechende Literatur zu dieser Spangenform verwiesen werden, die wohl auf provinzialrömische Vorlagen zurückgeht und unlängst als Typ Masłomęcz definiert wurde (Beliavec 2007, 314, Abb. 6; 13: 2; Droberjar 2018; Gałęzowska 2010, 250 ff.; Kokowski 1987, Abb. 29: a-c; 1995, 37; Niezabitowska-Wiśniewska 2015, 333 f., Abb. 2: 1). Gut datierbare Exemplare stammen aus der Subphase C1a. Die Konzentration der „Entenfibeln" zwischen Westlichem und Südlichem Bug (Pivdennij Buh) wird durch die Neufunde ${ }^{23}$ bestätigt und verdichtet, bemerkenswert ist allerdings eine Gruppe von Funden (von einer unbekannten Anzahl von Fundplätzen) im mittleren Dneprgebiet (Abb. 7). Sie lässt vermuten, dass in Zukunft weitere Belege aus dem Raum westlich des Dnepr erwartet werden können - wenn es sie nicht schon längst gibt und wir nur über ihre Auffindung nicht unterrichtet sind. Unklar ist aufgrund der Fundumstände, wie die vermutlich sämtlich „,vor-Černjachov-zeitlichen“ Funde von Fibeln des Typs Masłomęcz aus der Ukraine kulturell einzuordnen sind, diese Frage betrifft allerdings auffallend viele Funde, die in den letzten Jahren illegal geborgen wurden und unterstreicht die Dringlichkeit einer eingehenden Beschäftigung mit ihnen.

\footnotetext{
${ }^{21}$ Auf den einschlägigen Internetseiten werden oftmals nur die Oblasti angegeben und nur sehr selten genauere Angaben oder gar der Fundort selbst, sicher auch, um den „Claim“ des jeweiligen Sondengängers vor Konkurrenz zu schützen.

${ }^{22}$ Die Fotos auf Abb. 3 (außer Nr. 6) verdanke ich Jacek Andrzejowski (Warszawa), der ebenfalls zugängliche Daten zu illegal gesuchten und geborgenen Funden gesammelt hat. Ein Zusammenbruch des Servers, auf dem die Daten gespeichert waren, und zufällig wenig später der Ausfall der externen Festplatte mit den Sicherungskopien der Daten haben zur Folge, dass die Stücke zwar noch mit Fotos bezeugt sind, aber keinerlei Angaben zu ihrer Herkunft innerhalb der Ukraine mehr vorliegen.

${ }^{23}$ Fotos auf den Internetseiten www.violety.com und www.domongol.org [Zugriffe Januar 2018, März 2019, Februar 2020; Dezember 2020].
} 


\section{FUNDLISTE DER RINDERKOPFFIBELN}

\section{Polen}

1 Grunajki, pow. Gołdap, woj. warmińsko-mazurskie/ Gruneiken, Kr. Darkehmen.

Grab 12: drei Bügelprofilierungen, Hülsenscharnier; A V, Ser. 1, ähnlich Hauptmann Serie 4 - frühe Dreisprossenfibeln im Baltikum (Andrzejowski/Cieśliński 2007, Abb. 14: e; Tischler 1879, Taf. IX [III]: 15).

2 Kraśnik Piaski, pow. Kraśnik, woj. lubelskie. Grab 37: geknickter Bügel, breiter Kopfkamm, Hörner mitgegossen; A 132, Var. (Andrzejowski/Cieśliński 2007, Abb. 19: d; Wichrowski 1998, 108, Abb. 4: 3).

3. Łubiana, pow. Kościerzyna, woj. pomorskie. Hort: schmaler, knieförmig geknickter Bügel, Kopfknopf, obere Sehne, Hörner abgebrochen; A V, Ser. 9/A VII (Andrzejowski/Cieśliński2007, Abb. 19: c; Mączyńska 2011, 349, Taf. 9: F 18; 106: F 18).

4. Miętkie, pow. Szczytno, woj. warmińsko-mazurskie/ Mingfen, Kr. Ortelsburg.

Grab 3: massiver, geknickter Bügel; A 137, Var. (Andrzejowski/Cieśliński 2007, Abb. 14: a; Garte 1929, Abb. 169: a; Nowakowski 1998a, 117, Abb. 13: 304; Taf. 16: 304; Schmidt 1906, 461, Abb. 2).

5. Mojtyny, pow. Olsztyń, woj. warmińsko-mazurskie/ Moythienen, Kr. Sensburg.

Grab 1-7: 2 Ex. A V, Ser. 1, „masurischer Typ“ (Andrzejowski/Cieśliński 2007, Abb. 14: b-c; Hollack/Peiser 1904, 43, 44, Taf. I: d: $7 \mathrm{~b}$ ).

6. Nikutowo, pow. Mrągowo, woj. warmińsko-mazurskie/ Nikutowen, Kr. Sensburg.

S-förmiger Bügel mit dachförmigem Querschnitt, stabförmiger Kopfknopf, untere Sehne; A VII (Andrzejowskil Cieśliński 2007, Abb. 14: d; Gaerte 1929, Abb. 169: d).

7. Spychówko, pow. Szczytno, woj. warmińsko-mazurskie/ Klein Puppen, Kr. Ortelsburg.

2 Ex. A V, Ser. 1, ,'masurischer Typ“; Hörner mitgegossen (Andrzejowski/Cieśliński 2007, Abb. 14: f; Gaerte 1929, Abb. 169: b; Hollack/Peiser 1904, 24 f.; Nowakowski 2016b, Abb. 3: 1).

8. Opalenie, pow. Tczew, woj. pomorskie.

Grab 122: breiter, S-förmiger Bügel mit Kopfkamm und rechteckigem „Aufsatz" (Andrzejowski/Cieśliński 2007, 294, Abb. 17; Tuszyńska 2005, 435, Taf. I: 3).

9. Świerczyna, pow. Drawski, woj. zachodniopomorskie/ Groß-Linichen, Kr. Dramburg.

Grab 3: breiter, geknickter Bügel mit dachförmigem Querschnitt, Kopf mit breitem und flachem Kamm, hoher Nadelhalter; A 125/A 132, Var. (Andrzejowski/ Cieśliński 2007, 295 f., Abb. 19: b; Gandert 1957, 137, Anm. 76, Abb. 2).

\section{Ukraine}

10. Chmel'nyc'ka oblast' (Хмельницька область).

Detektorfund: breiter, leicht geknickter Bügel, Kopfkamm (Machajewski Form 7b/A 132); Hörner mitgegossen (Abb. 2: 4).

11. Červonochyžynci, Čerkas'ka oblast' (Червонохижинці, Черкаська область).

Detektorfund: ,"kräftig profilierte“ Fibel mit extrem hohem Bügelkamm, stark verbreitertem Kopf, Sehnenhaken und oberer Sehne, Hörner mitgegossen, Bügelkamm durchlocht und mit einhängendem Ring (Magomedov/ Kuštan 2002).
12. Dnipropetrovs'ka oblast' (Дніпропетровська область). Detektorfund: annähernd S-förmiger Bügel, stabartige Kopfverlängerung (A VII); Hörner mitgegossen (Abb. 2: 3).

13. Medžybiž, Letyčivs'kiy rayon, Chmel'nyc'ka oblast' (Меджибіж, Летичівський район, Хмельницька область).

Detektorfund: S-förmiger Bügel, hoher Nadelhalter (A VII); Hörner mitgegossen (Abb. 2: 1).

14. Odes'ka oblast' (Одеська область).

Detektorfund: knieförmig (A 137 Var.); Hörner mitgegossen (Abb. 2: 2).

15.-21. „Ukraine“. Sieben Exemplare ohne nähere Lokalisierung (Detektorfunde):

15. Annähernd knieförmig geknickter Bügel mit Kopfverdickung; Sehnenhaken; typologisch nicht genau anzusprechen, ähnlich Cociş Typ 32b2 (Abb. 3: 1).

16. Knieförmig geknickter Bügel mit Rillengruppenverzierung; hoher Nadelhalter; A 137, Var. (Abb. 3: 2).

17. Knieförmig geknickter, in der Sicht von oben zum Kopf hin stark breiter werdender Bügel, halbkreisförmige Kopfplatte, offenbar obere Sehne; A V, Serie 8, aber auch ähnlich Jobst 13D (Abb. 3: 3).

18. „Kräftig profilierte“ Fibel mit extrem hohem Bügelkamm, stark verbreitertem Kopf mit lappenartigen Enden und oberer Sehne, die augenscheinlich durch eine Durchlochung des Steges am Bügelkopf geführt ist; A IV, Var. (Abb. 3: 4).

19. „Kräftig profilierte“ Fibel mit extrem hohem Bügelkamm, verbreitertem Kopf mit lappenartigen Enden und ösenartigem Steg am Kopf zur Aufnahme der Spiralachse; Bügelkamm mehrfach durchlocht; A IV, Var. (Abb. 3: 5).

20. „Kräftig profilierte“ Fibel mit vermutlich verbreitertem Kopf, mit Steg mit zwei Durchlochungen für Spiralachse und obere Sehne; A IV, Var. (Abb. 3: 7).

21. Mit drei Bügelprofilierungen und Hülsenscharnier; ähnlich Hauptmann Serie 4, „frühe Dreisprossenfibeln im Baltikum" (Abb. 3: 8).

\section{Österreich}

22. Ringelsdorf, MG Ringelsdorf-Niederabdorf, VB Gänserndorf.

Detektorfund: bolzenförmiger, geknickter Bügel, Hörner auf Höhe des Bügelknicks, hoher Nadelhalter; A V, Ser. 9/A VII); Interpretation unsicher (FÖ 2000, 664, Abb. 826).

\section{Deutschland}

23. Zauschwitz, Kr. Leipziger Land, Sachsen.

Grab 25: A VII, eher westliche Serie (Meyer 1969, 122, Abb. 37: 1).

\section{Rumänien}

24. Siebenbürgen.

Knieförmig; A 137, Var. (Cociş 2004, 116, 205, Taf. CI: 1426).

\section{Osteuropa}

25. Vermutlich Ukraine. „Kräftig profilierte“ Fibel mit verbreitertem Kopf, mit Öse für die Spiralachse und Sehnenhaken; Bügelkamm dreifach durchlocht; A IV, Var. (Abb. 3: 6). 


\section{LITERATUR}

Ambroz 1966 - A. K. Ambroz: Fibuly juga evropejskoj časti SSSR. II v. do n. e. $-I V$ v. n. e. Archeologija SSSR. Svod archeologičeskich istočnikov D1-30. Moskva 1966.

Andrzejowski, im Druck-J. Andrzejowski: The Eastern Zone of the Przeworsk culture - and What it Comprehends. Acta Archaeologica Carpatica 55, im Druck.

Andrzejowski/Cieśliński 2007 - J. Andrzejowski/A. Cieśliński: Germanie i Bałtowie u schyłku starożytności. Przyjazne związki czy wrogie sąsiedztwo? In: A. Bitner-Wróblewska/W. Nowakowski (red.): Kultura bogaczewska w 20 lat później. Materiały z konferencji, Warszawa 26-27 marca 2003. Seminarium Bałtyjskie 1. Warszawa 2007, 279-319.

Andrzejowski/Maciałowicz 2017 - J. Andrzejowski/A. Maciałowicz: Między północą a południem. Zespół osadniczy z późnej epoki żelaza w Jarnicach nad Liwcem w świetle dalekosiężnych powiązań. Wiadomości Archeologiczne 68, 2017, 179-234.

DOI: https://doi.org/10.36154/wa.68.2017.09

Beilke-Voigt 2006 - I. Beilke-Voigt: Das Tieropfer in archäologischen und weitere Quellenzeugnissen. Ethnographisch-Archäologische Zeitschrift 47, 2006, 87-102.

Beliavec 2007 - V. G. Beliavec: K izučeniju pamiatnikov vel'barskoj kultury v Belarusi. In: M. Fudziński/H. Paner (red.): Nowe materiaty i interpretacje. Stan dyskusji na temat kultury wielbarskiej. Gdańsk 2007, 293-344.

Blankenfeldt 2007 - R. Blankenfeldt: Der bilderfeindliche Germane? In: Ch. Grünewald/T. Capelle (Hrsg.): Innere Strukturen von Siedlungen und Gräberfeldern als Spiegel gesellschaftlicher Wirklichkeit? Akten des 57. Sachsensymposions vom26. bis 30. August 2006 in Münster. Veröffentlichungen der Altertumskommission im Provinzialinstitut für Westfälische Landes- und Volksforschung. Landschaftsverband Westfalen-Lippe 17. Münster 2007, 99-107.

Blankenfeldt 2015 - R. Blankenfeldt: Die persönlichen Ausrüstungen. Das Thorsberger Moor 2. Schleswig 2015.

Böhme 1972 - A. Böhme: Die Fibeln der Kastelle Saalburg und Zugmantel. Saalburg-Jahrbuch 29, 1972, 5-112.

Bursche 2013 - A. Bursche: The Battle of Abritus, the Imperial Treasury and Aurei in Barbaricum. The Numismatic Chronicle 173, 2013, 151-170.

Bursche/Myzgin 2020 - A. Bursche/K. Myzgin: The Gothic Invasion of the mid- $3^{\text {rd }} \mathrm{c}$. AD and the Battle of Abritus: Coins and Archaeology in East-Central Barbaricum. Journal of Roman Archaeology 33, 2020, 195-229. DOI: https://doi.org/10.1017/S1047759420000987

Chilińska-Früboes 2020 - A. Chilińska-Früboes: Fibel, Tracht und Interkulturalität. Die Dollkeim/Kovrovo-Kultur der älteren Römischen Kaiserzeit im nördlichen Ostpreußen. Studien zur Siedlungsgeschichte und Archaologie der Ostseegebiete 18. Kiel - Hamburg 2020.

Cociş 2004 - S. Cociş: Fibulele din Dacia Romană. Bibliotheca Ephemeris Napocensis 3. Cluj-Napoca 2004.

Dąbrowska 1993-1994 - T. Dąbrowska: Późne odmiany fibul silnie profilowanych w Polsce. Wiadomości Archeologiczne 53, 1993-1994, 3-35.

Droberjar 2012 - E. Droberjar: Nová varianta spony typu Almgren 132 z Jevíčka. K přechodným formám Almgrenovy skupiny ve stupni B2/C1. In: G. Březinová/ V. Varsik (Hrsg.): Archeológia na prahu histórie. Kživotnému jubileu Karola Pietu. Archaeologica Slovaca Monographiae. Communicationes 15. Nitra 2012, 235-245.
Droberjar 2018 - E. Droberjar: Eine Vogelfibel mit hohem Nadelhalter vom Typ Masłomęcz aus Vrbová Lhota (Mittelböhmen). In: B. Niezabitowska-Wiśniewska/ P. Łuczkiewicz/S. Sadowski/M. Stasiak-Cyran/M. Erdrich (red.): Studia Barbarica. Profesorowi Andrzejowi Kokowskiemu w 65. rocznice urodzin. Tom II. Lublin 2018, 74-84.

Dulęba/Schuster 2012 - P. Dulęba/J. Schuster: Eine kaiserzeitliche Rinderfigur aus Kupferlegierung von einem Siedlungsplatz der Przeworsk-Kultur. Archäologisches Korrespondenzblatt 42, 2012, 387-399.

Dzięgielewska/Kulczyńska 2008 - M. Dzięgielewska/M. Kulczyńska: Ciebłowice Duże. Ein Gräberfeld der Przeworsk-Kultur im südwestlichen Masowien. Monumenta Archaeologica Barbarica 14. Warszawa 2008.

Eggers 1951 - H. J. Eggers: Der römische Import im freien Germanien. Atlas zur Urgeschichte 1. Hamburg 1951.

Eggers/Stary 2001 - H. J. Eggers/P. F. Stary: Funde der Vorrömischen Eisenzeit, der Römischen Kaiserzeit und er Völkerwanderungszeit in Pommern. Beiträge zur Ur- und Frühgeschichte Mecklenburg-Vorpommerns 38. Lübstorf 2001.

FÖ 2000 - Fundberichte aus Österreich 39, 2000.

Gaerte 1929 - W. Gaerte: Urgeschichte Ostpreußens. Ostpreußische Landeskunde in Einzeldarst 1. Königsberg i. Pr. 1929.

Gałęzowska 2010 - A. Gałęzowska: Znaleziska z okresu rzymskiego z terenu Ukrainy w zbiorach Muzeum Archeologicznego w Poznaniu. In: A. Urbaniak/ R. Prochowicz (red.): Terra Barbarica. Studia ofiarowane Magdalenie Mączyńskiej w 65. rocznice urodzin. Monumenta Archaeologica Barbarica. Series Gemina 2. Łódź - Warszawa 2010, 251-260.

Gandert 1957 - O. F. Gandert: Das bronzene Rinderfigürchen von Berlin-Schöneberg. Berliner Blätter für Vor- und Frühgeschichte 6, 1957, 108-152.

Godłowski/Wichman 1998 - K. Godłowski/T. Wichman: Chmielów Piaskowy. Ein Gräberfeld der Przeworsk-Kultur im Świętokrzyskie-Gebirge. Monumenta Archaeologica Barbarica 6. Kraków 1998.

Hegewisch 2018 - M. Hegewisch: Tierdarstellungen auf germanischer Keramik. Eine kurze Besprechung der abgebildeten Tierarten. In: M. Ljubičev/K. Myzgin (Hrsg.): Chronologie und Münzfunde der späten römischen Kaiserzeit und Völkerwanderungszeit. Aktuelle archäologische Forschungen in Zentral- und Osteuropa. Materialien des Feldseminars an der Basis der Expedition bei Vojtenki 15.-17. September 2016. Ostrogothica. Heft 3. Charkov 2018, 146-181.

Hollack/Peiser 1904 - E. Hollack/F. E. Peiser: Das Gräberfeld von Moythienen. Königsberg i. Pr. 1904.

Jobst 1975 - W. Jobst: Die römischen Fibeln aus Lauriacum. Forschungen in Lauriacum 10. Linz 1975.

Kokowski 1987 - A. Kokowski: Grupa masłomęcka w okresie rzymskim (III-IV wiek naszej ery). Lublin 1987.

Kokowski 1995 - A. Kokowski: Grupa masłomęcka. Z badań nad przemianami kultury Gotów w młodszym okresie rzymskim. Lublin 1995.

Kovrig 1937 - I. Kovrig: Die Haupttypen der kaiserzeitlichen Fibeln in Pannonien. Dissertationes Pannonicae. Ser. II. Fasc. 4. Budapest 1937.

Levada/Potupčik 2017 - M. Levada: M. Potupčik: Nowe eksponaty z okresu wpływów rzymskich w Muzeum 
Krajoznawczym w Winnicy. In: J. Andrzejowski/ A. Cieśliński/B. Kontny (red.): Orbis barbarorum. Studia ad archaeologiam Germanorum et Baltorum tempudoribus Imperii Romani pertinentia Adalberto Nowakowski dedicata. Monumenta Archaeologica Barbarica. Series Gemina 6. Warszawa - Schleswig 2017, 409-420.

Mączyńska 2011 - M. Mączyńska: Der frühvölkerwanderungszeitliche Hortfund aus Łubiana, Kreis Kościerzyna (Pommern). Bericht der Römisch-Germanischen Kommission 90, 2011, 7-482.

Magomedov/Kuštan 2002 - B.V. Magomedov/D. P. Kuštan: Fibula z holovoju byka z Čerkaskoji oblasti. Archeolohija 3, 2002, 66, 67.

Maier 1981 - F. Maier: Eine germanische Stierfigur der späten Kaiserzeit aus dem Rhein-Main-Gebiet. Germania 59, 1981, 331-356.

Martens 1999 - J. Martens: En halsring med fugleformede endestykker fra Nordre Rør, Østfold. Om betydningen af de zoomorfisk udsmykkede genstande fra afslutningen af den yngre føromersk jernalder. Universitets Oldsaksamling Arbok, 1999, 41-74.

Merczi 2011 - M. Merczi: Térdfibulák Komárom-Esztergom Megyéből. Komárom-Esztergom Megyei Múzeumok Közleményei 17, 2011, 7-80.

Merczi 2012 - M. Merczi: A Budaörs-Kamaraerdei-Dülőben feltárt római vicus fibulái. In: K. Ottományi (szerk.): Római vicus Budaörsön. Régészeti tanulmányok. Budapest 2012, 473-528.

Meyer 1969 - E. Meyer: Das germanische Gräberfeld von Zauschwitz, Kr. Borna. Arbeits- und Forschungsberichte zur sächsischen Bodendenkmalpflege. Beiheft 6. Berlin 1969.

Nadvirniak/Pohorilec' 2014 - O. V. Nadvirniak/O. H. Pohorilec': Novi znachidki bronzovych kazaniv typu Hemmoor na Podilli. Oium 4, 2014, 151-155.

Natuniewicz-Sekuła 2015-2016 - M. Natuniewicz-Sekuła: Weklice, stan. 7, pow. elbląski, woj. warmińskomazurskie. Badania w latach 2015-2016. Swiatowit 13-14 (54-55), fascykul A/B, 2015-2016, 235-240.

Natuniewicz-Sekuła/Okulicz-Kozaryn 2011 - M. NatuniewiczSekuła/J. Okulicz-Kozaryn: Weklice. A Cemetery of the Wielbark Culture on the Eastern Margin of Vistula Delta (Excavations 1984-2004). Monumenta Archaeologica Barbarica 17. Warszawa 2011.

Niezabitowska-Wiśniewska 2015 - B. Niezabitowska-Wiśniewska: Ulów, stanowisko 7 - nowe cmentarzysko kultury wielbarskiej na Roztoczu Środkowym - z badań nad kontaktami kultury wielbarskiej i kultury czerniachowskiej. In: M. Fudziński/H. Paner (red.): Kontakty ponadregionalne kultury wielbarskiej. Przemiany kulturowe w okresie wptywów rzymskich na Pomorzu. Gdańsk 2015, 331-362.

Nowakowski 1989 - W. Nowakowski: Kultura wielbarska a zachodniobałtyjski kragg kulturowy. In: J. Gurba/A. Kokowski (red.): Kultura wielbarska w młodszym okresie rzymskim (materialy z konferencji). Tom 2. Lublin 1989, 143-159.

Nowakowski 1998a - W. Nowakowski: Die Funde der römischen Kaiserzeit und der Völkerwanderungszeit in Masuren. Bestandkataloge des Museums für Vor- und Frühgeschichte 6. Berlin 1998.

Nowakowski 1998 - W. Nowakowski: Die Nebenformen Almgren 133 und 137 aus heutiger Sicht. In: J. Kunow (Hrsg.): 100 Jahre Fibelformen nach Oscar Almgren. Internationale Arbeitstagung 25.-28. Mai 1997 Kleinmachnow,
Brandenburg. Forschungen zur Archäologie im Land Brandenburg 5. Wünsdorf 1998, 197-201.

Nowakowski 2016a - W. Nowakowski: Die zwei völkerwanderungszeitlichen Stierfibeln aus Masuren. In: B. Chudzińska/M. Wojenka/M. Wołoszyn (red.): Od Bachórza do Światowida ze Zbrucza. Tworzenie się słowiańskiej Europy w ujęciu źródłoznawczym. Księga jubileuszowa Profesora Michała Parczewskiego. Krakow - Rzeszów 2016, 105-111.

Nowakowski 2016b - W. Nowakowski: Items with the oxhead on the shores of the Baltic Sea in the Roman Period. Archaeologia Baltica 23, 2016, 129-139.

DOI: https://doi.org/10.15181/ab.v23i0.1300

Nowakowski 2017 - W. Nowakowski: Okucie rogu do picia z Legionowa na tle znalezisk plastyki bukefalicznej w Barbaricum (zarys problematyki i kierunkow planowanych poszukiwań badawczych). In: W. Nowakowski/ W. Orliński/M. Woińska (red.): Relacje kultury przeworskiej i lateńskiej na Mazowszu. Wnioski z badań cmentarzyska przeworskiego w Legionowie CSP. Legionowo Warszawa 2017, 119-134.

Orliński 2011 - W. Orliński: Okucie rogu do picia zakończone głową byka z cmehtarzyska kultury przeworskiej w Legionowie, pow. loco. Wiadomości Archeologiczne 62, 2011, 241-243.

Oxenstierna 1956 - E. Oxenstierna: Die Goldhörner von Gallehus. Lidingö 1956.

Pawlak 2008 - E. Pawlak: Cmentarzysko ludności kultury przeworskiej w Osieku, pow. Jarocin. In: H. Machajewski (red.): Wielkopolska w dziejach. Archeologia o regionie. Poznań 2008, 207-213.

Pesch 2011a - A. Pesch: Gehörnte Pferde. Elitenkommunikation und synthetische Tradition am Beginn germanischer Bildkunst. In: B. Ludowici/H. Pöppelmann: Das Miteinander, Nebeneinander und Gegeneinander von Kulturen. Zur Archäologie und Geschichtewechselseitiger Beziehungen im 1. Jahrtausend n. Chr. Neue Studien zur Sachsenforschung 2. Stuttgart 2011, 9-17.

Pesch 2011b - A. Pesch: Dicke Vögel und gehörnte Pferde. Frühe Etablierung protostaatlicher Strukturen im Spiegel der Bilder. In: L. Boyé (Hrsg.): Arkologi i Slesvig/Archäologie in Schleswig. Sonderband "Det 61. Internationale Sachsensymposion 2010“, Haderslev, Danmark. Neumünster 2011, 45-56.

Peškař 1972 - I. Peškař: Fibeln aus der römischen Kaiserzeit in Mähren. Praha 1972.

Petković 2010 - S. Petković: Rimske fibule z Srbiji od I do V veka n.e. Arheološki institut. Posebna izdanja. Knjiga 50. Beograd 2010.

Petrauskas/Didenko 2019 - O. V. Petrauskas/S. V. Didenko. Znachidky ryms'kych rečej z pivničnoho Podillja (novi nadchodžennja do fondiv Nacional'noho muzeju istorii Ukrainy. Oium 6, 2019, 148-168.

Pieta 2006 - K. Pieta: Ein junglatènezeitlicher Stieranhänger aus Udiča/Slowakei. In: W.-R. Teegen et al. (Hrsg.): Studien zur Lebenswelt der Eisenzeit. Festschrift für Rosemarie Müller. Ergänzungsbände zum Reallexikon der Germanischen Altertumskunde 52. Berlin - New York 2006, 133-147.

Pieta 2010 - K. Pieta: Die keltische Besiedlung der Slowakei. Jüngere Latènezeit. Archaeologica Slovaca Monographiae. Studia 12. Nitra 2010.

Prochowicz/Rakowski 2013 - R. Prochowicz/T. Rakowski: Sieluń, pow. makowski - nowe stanowisko kultury wielbarskiej na północnym Mazowszu. Wiadomości Archeologiczne 64, 2013, 198-210. 
Rajtár 2018 - J. Rajtár: Die Fibeln vom Typ Almgren 43. In: B. Niezabitowska-Wiśniewska/P. Łuczkiewicz/ S. Sadowski/M. Stasiak-Cyran/M. Erdrich (red.): Studia Barbarica. Profesorowi Andrzejowi Kokowskiemu w 65. rocznice urodzin. Tom II. Lublin 2018, 52-72.

Rasmussen 2007 - B. M. Rasmussen: Trinkhornbeschläge aus Schleswig - ein Magazinfund. Über die rinderkopfförmigen Trinkhornbeschläge der Römischen Kaiserzeit und ihre Funktion. In: S. Burmeister/H. Derks/J. von Richthofen (Hrsg.): Zweiundvierzig. Festschrift für Michael Gebühr zum 65. Geburtstag. Internationale Archäologie. Studia Honoraria 25. Rahden/Westf. 2007, 191-206.

Redžić 2007 -S. Redžić: Nalazy rimskih fibula na nekropolama Viminacijuma. Arheologija i Prirodne Nauke. Posebna Izdanja 2. Beograd 2007.

Schmidt 1906 - H. Schmidt: Ostpreußische Beiträge. Zeitschrift für Ethnologie 38, 1906, 456-484.

Schoknecht 2006 - U. Schoknecht: Zu den Rinderfigürchen aus Mecklenburg-Vorpommern. Archäologische Berichte aus Mecklenburg-Vorpommern 13, 2006, 33-39.

Schulte 2011 - L. Schulte: Die Fibeln mit hohem Nadelhaltert (Almgren Gruppe VII). Göttinger Schriften zur Vor- und Frühgeschichte 32. Neumünster 2011.

Schuster 2001 - J. Schuster: Einige Elemente aus dem westbaltischen Kulturkreis, der Wielbark- und der Przeworsk-Kultur in den Gebieten westlich der Oder ab dem späten zweiten Jahrhundert. In: M. Meyer (Hrsg.): „... Trans Albim fluvium“ Forschungen zur vorrömischen, kaiserzeitlichen und mittelalterlichen Archäologie. Festschrift für Achim Leube zum 65. Geburtstag. Internationale Archäologie. Studia Honoraria 10. Rahden/Westf. 2001, 417-429.

Schuster/Dulęba 2012 - J. Schuster/P. Dulęba: Eine kaiserzeitliche Rinderfigur aus Kupferlegierung von einem Siedlungsplatz der Przeworsk-Kultur. Archäologisches Korrespondenzblatt 42, 2012, 387-399.

Sekuła 2006 - M. Sekuła: Ocalałe zabytki pochodzące z badań niemieckich na cmentarzysku w Malborku-Wielbarku w zbiorach muzeów polskich. In: W. Nowakowski/A. Szela (red.): Pogranicze trzech światów. Kontakty kultur przeworskiej, wielbarskiej i bogaczewskiej w świetle materiałów z badań i poszukiwań archeologicznych. Światowit. Supplement. Series P. Prehistory and Middle Ages 14. Warszawa 2006, 175-223.

Skvorcov 2014 - K. N. Skvorcov: Zniszczony pochówek z zawieszką lunulowatą z Półwyspu Sambijskiego. Wiadomości Archeologiczne 65, 2014, 277-283. DOI: https://doi.org/10.36154/wa.65.2014.14

Manuskript angenommen am 28. 5. 2021

Abstract translated by author
Skvorzov/Pesch 2011 - K. Skvorzov/A. Pesch: Krieger, dicke Vögel und gehörnte Pferde? Ein Sattelbeschlag aus Mitino (Obl. Kaliningrad). Archäologisches Korrespondenzblatt 41, 2011, 419-438.

Stenberger 1946 - M. Stenberger: Djurfigurer från äldre järnålder. Fornvännen 41, 1946, 149-165.

Szter 2010 - I. Szter: Cmentarzysko z okresu wpływów rzymskich i z okresu wędrówek ludów w Kamieniu na Pojezierz Mazurskim. Wiadomości Archeologiczne 61, 2010, 201-331.

Teßmann 2009 - B. Teßmann: Drei Pferdefigürchen aus dem Berliner Museum für Vor- und Frühgeschichte. Zur Verbreitung und Funktion bronzener Tierplastiken der älteren Eisenzeit. Acta Praehistorica et Archaeologica 41, 2009, 189-205.

Thrane 1989 - H. Thrane: Bovidenstatuetten von Fünen. Frühmittelalterliche Studien 23, 1989, 363-416.

Tischler 1879 - O. Tischler: Ostpreussische Gräberfelder III. Schriften der Physikalisch-Ökonomischen Gesellschaft zu Königsberg 19, 1879, 159-269.

Tischler 1950 - F. Tischler: Über einige Trinkhornendbeschläge in Form eines Stierkopfes aus der römischen Kaiserzeit. Praehistorische Zeitschrift 34-35, 1950, 374-384.

Tischler/Kemke 1902 - O. Tischler/H. Kemke: Ostpreussische Altertümer aus der Zeit der grossen Gräberfelder nach Christi Geburt. Königsberg i. Pr. 1902.

Tuszyńska 2005 - M. Tuszyńska: Cmentarzysko w Opaleniu, gmina Gniew, stanowisko 1. Badania 2001-2003. In: M. Fudziński/H. Paner (red.): XIV sesja pomorzoznawcza. Vol. 1. Od epoki kamienia do okresu rzymskiego. Gdańsk 2005, 435-440.

Werner 1966 - J. Werner: Das Aufkommen von Bild und Schrift in Nordeuropa. Bayerische Akademie der Wissenschaften, Phil.-hist. Klasse. Sitzungsberichte 4. München 1966.

Wichrowski 1998 -Z. Wichrowski: Badania archeologiczne na cmentarzysku kultury przeworskiej w KraśnikuPiaskach, stan. 2, woj. Lubelskie. Archeologia Polski Środkowowschodniej 3, 104-109.

Wiśniewska 2011 - A. Wiśniewska: Materiały z cmentarzyska w Leśniewie, pow. kętrzyński (dawne Fürstenau, Kr. Rastenburg). Wiadomości Archeologiczne 62, 2011, 119-167.

Worbs 1979 - R. Worbs: Zethlingen, ein Brandgräberfeld der spätrömischen Kaiserzeit aus der Altmark. Wissenschaftliche Beiträge der Martin-Luther-Universität Halle-Wittenberg. Band 1979/12. Reihe L. Vor- und frühgeschichtliche Beiträge. Band 14. Halle/Saale 1979.

prof. dr hab. Jan Schuster

Instytut Archeologii Uniwersytetu Łódzkiego

Narutowicza 65

PL - 90-131 Łódź

jan.schuster@uni.lodz.pl 
